\title{
Farmers and Ranchers in North Dakota Value Their Land in Not Only Economic Terms
}

Cindy L. Juntunen, Michael F. Gallina, Tamba-Kuii M. Bailey, Megan L. Hunsaker, Rebecca Burandt, Teresa L. Huff-Pomstra, Jennifer A. Munch, Katelyn Burshek, Evelyn Ayala, and Michael P. Huttar

Counseling Psychology and Community Services, University of North Dakota, Grand Forks, North Dakota.

\section{Abstract}

Beliefs and attitudes are a critical component of future behaviors yet remain underexamined when assessing the intentions of agricultural producers to implement conservation practices. We examined the antecedents to agricultural behavior through qualitative interviews analyzed with consensual qualitative research (Hill, Thompson, \& Nutt Williams, 1997) methodology. The results indicated complex relationships between stewardship beliefs and economic factors, as well as influences related to science and technology, weather and climate, and threats to family farm identity. Analyzing the findings using tenets of the theory of planned behavior (Ajzen, 1991), we present implications for interventions with agricultural producers as well as psychological theory and research, and suggest that farmers and ranchers value the land in important ways that extend beyond economic considerations. Key Words: Farmer attitudes-Land useQualitative study.

\section{Introduction}

he Fourth National Climate Assessment (USGCRP, 2017) concluded that US agricultural producers will be dramatically impacted by climate and environmental changes and laid out numerous adaptive strategies for consideration. This is only the most recent attention paid to the interaction between farming and climate change, as climate change has been identified as an increasingly large risk to the agricultural industry (Arbuckle, Morton, \&t Hobbs, 2013; Melillo, Richmond, \& Yohe, 2014).

Conversely, the agriculture industry may also contribute to changing environmental conditions. The US government has attempted to mitigate the effects of environmentally damaging agricultural practices by allocating billions of dollars to conservation policies and programs to help agricultural producers adapt their practices (Wilke \& Morton, 2015). However, convincing farmers and ranchers to change their practices can be a difficult process (Wilke $\&$ Morton, 2015). As noted by Lyle (2015), farmers must believe that climate change is a threat to their operation before they adopt conservation strategies. Some researchers have found that farmers agree that the climate is indeed changing (Prokopy, Morton, Arbuckle, Mase, \& Wilke, 2015). However, they tend to be opposed to the notion that the climate can be affected by their practices (Arbuckle et al., 2013; Wilke \& Morton, 2015) or negatively affect their productivity (Rejesus, Mutuc-Hensley, Mitchell, Coble, \&t Knight, 2013). Further, agricultural producers who are optimistic about the potential for technology or human ability to reduce the impact of climate change are also less likely to engage in conservation adaption practices (Gardezi \&t Arbuckle, 2018).

Such findings reinforce previous conclusions that social and cognitive factors play a critical role in whether or not agricultural producers make environmentally sound decisions (Gardezi \&t Arbuckle, 2018) or participate in conservation programs. However, most examinations of farmer-environment interaction focus on economic motivations and agricultural policies and practices; few have studied the psychological factors that may influence farmer behavior (Borges $\&$ Oude Lansink, 2016; Hansson, Ferguson, \&t Olofsson, 2012).

The emphasis on economic factors fails to fully explain conservation and adaptation decisions and behaviors (Lynne, Shonkwiler, \&t Rola, 


\section{JUNTUNEN ET AL.}

1988; Thompson, Reimer, \& Prokopy, 2015). When additional attitudinal factors have been considered, the focus is typically on attitudes of stewardship (Chouinard, Paterson, Wandschneider, \& Ohler, 2008; Thompson et al., 2015). This bidirectional examination of willingness to adopt conservation practices on an economic/ stewardship continuum has minimized and overlooked other psychosocial factors. Thus, it is important that research examines underlying attitudes and other psychological factors. In order to develop a broader understanding of motivating factors among agricultural producers, the current study is anchored in the assumption that attitudes and beliefs among agricultural producers are highly relevant to conservation behavior and that they can be understood as contributing to either increased or decreased proenvironmental behaviors.

\section{Current study}

Given existing gaps in the literature, it is apparent that there is benefit to more carefully studying and examining psychological factors, including attitudes and beliefs, among farmers and ranchers. Further, there have been calls for qualitative studies to better understand the factors that affect farmers' and ranchers' decisionmaking related to conservation practices (Prokopy, 2011). Therefore, the current study utilized consensual qualitative research (CQR) (Hill, Thompson, \& Nutt Williams, 1997) to identify social, economic, and other factors that may influence the decisions North Dakota farmers and ranchers make about agricultural practices. $\mathrm{CQR}$ is a qualitative methodology that has been used extensively in psychological and social science research (Hill, 2012). Based on its methodological rigor, established performance across two decades, and defined philosophical underpinnings, CQR provides a qualitative methodology that meets the suggested elements of quality in ecological research: dependability, credibility, confirmability, and transferability (Moon, Brewer, Januchowski-Harley, Adams, \& Blackman, 2016).

\section{Methods}

\section{Participants}

Participants included 19 farmers and ranchers living across North Dakota. The sample consisted of 6 farmers who primarily grew crops, 5 ranchers who primarily raised livestock, and 8 who did both. The most commonly grown crops were soybeans, canola, and small grains. The most common livestock was cattle, with some representation of hogs and goats. Three (16\%) of the participants self-identified as female, and $16(84 \%)$ self-identified as male. Participants ranged in age from 26 to $79(M=54.53, S D=14.41)$ and all identified as White. They reported working in agriculture from 5 to 70 years $(M=34.12, S D=20.61)$, with three participants noting that they had farmed "all my life." Most $(91.7 \%)$ owned their farmland, with two reporting that they worked on rented land only. North Dakota does not allow farming by corporations that are not solely owned by families; therefore, the land ownership and family ties to farming and land may be more homogeneous than in other regions. Because of the low representation, we did not analyze differences between participants who farmed their own land and those farming rented land.

\section{Procedure}

Recruitment. Participants were recruited through community centers, county extension agents, social media ads and announcements, and researcher recruitment booths at county fairs and $4 \mathrm{H}$ events. Once interested participants were identified, snowball recruitment was also used in that participants were invited to recommend the study to others who were involved in farming or ranching.

Interview protocol and procedure. A semistructured interview protocol (see Appendix A1) was used. Consistent with recommendations by CQR developers (Hill et al., 1997), the interview protocol included eight questions and a variety of follow-up prompts. This balance allowed for consistency across interviews yet supported depth and richness of data by providing leeway to follow up on content emerging spontaneously in each interview.

Interviews were conducted face-to-face or via telephone, either individually or in a focus group setting. After providing consent, participants completed a demographics form and then were asked the interview questions. One focus group $(N=7), 10$ individual interviews, and one interview with a married couple (both of whom were actively involved in farming) were conducted. An analysis of content was conducted to ensure that the focus group did not differ significantly from the individual interviews, and the only difference detected was related to the unique characteristics of the crops produced. No significant differences in the emergent domains or core ideas were identified, so the data from the focus group was included in the analysis. Following the interview, each participant was provided with a $\$ 25$ gift card.

Data analysis. The analysis of data was conducted in multiple rounds of independent and consensual coding and auditing, according to the guidelines of CQR (Hill et al., 1997). The first two transcripts were reviewed and independently coded by all team members. The team then met as a group and discussed each code until they agreed, or came to consensus, on the meaning of the participant's statement. After consensus was reached on two transcripts, the remaining transcripts 
FARMERS' AND RANCHERS' BELIEFS AND ATTITUDES

were divided so that each was read by two members of the research team. Those reading pairs then came to consensus on each transcript they were assigned. In the final state of domain coding, the full team met and discussed all the domains and core ideas that had emerged across the transcripts and organized them using consensual discussion.

The emerging domains and core ideas were sent to an auditor who was not involved in the consensus discussion. The auditor provided feedback on the six original domains, which resulted in them being condensed into five domains, and examined emerging core ideas for consistency. The auditor's comments were integrated into the cross-case analysis, during which individual core ideas and themes were collapsed across transcripts. The cross analysis resulted in a final table of domains and core ideas, which was again sent to the auditor for a final audit. The auditor's impression was that the cross-case analysis fit the data well, and that set of domains and core ideas is presented in the findings that follow.

Although CQR is a primarily qualitative methodology, one of the steps in the process that helps to establish dependability and confirmability of the data (Moon et al., 2016) is the evaluation of the frequency of the domains and core ideas as general, typical, or variant. General ideas are referenced by all of the participants, typical ideas are those endorsed by a majority of the participants, and variant ideas are important ideas introduced by less than half but more than two of the participants.

\section{Results}

The results for each of the domains and core ideas are presented in Table 1. Based on the analysis of the data, five domains emerged. The domains were (1) Weather and Climate, (2) Technology and Science, (3) Emotional and Familial Connectedness, (4) Economics, and (5) Threats to Family Farm Identity.

\section{Weather and Climate}

All the participants indicated that weather played a major role in the way they made decisions about land use. These participants have made their living in a harsh and unforgiving climate, and constant monitoring of the weather is part of daily life. Participant 10 noted, "I'm not a meteorologist, but we plan around the weather as much as possible." Within the overarching domain of Weather and Climate emerged three distinct core ideas: (1) weather cycles have always existed, (2) readiness for weather events, and (3) variable attitudes toward climate change.

The core idea of weather cycles have always existed represents participants' beliefs regarding the nature of weather. Also, the participants recognized that these cycles impact their agricultural practices. Participant 7, a farmer, offered the following statement related to weather cycles:

\begin{tabular}{|c|c|}
\hline DOMAIN AND CORE IDEA & FREQUENCY \\
\hline Weather and Climate & General \\
\hline Weather cycles have always existed & Typical \\
\hline Readiness for weather events & Typical \\
\hline Variable attitudes toward climate change & Typical \\
\hline Technology and Science & General \\
\hline Changing practices & General \\
\hline Scientific mindedness & Typical \\
\hline Handheld devices & Typical \\
\hline Increased efficiency & Variant \\
\hline Emotional and Familial Connectedness & General \\
\hline Multigenerational & General \\
\hline Stewardship/Responsibility & Typical \\
\hline Passion/love for farming & Typical \\
\hline Economics & Typical \\
\hline Market fluctuations & Typical \\
\hline Government programs & Typical \\
\hline Labor issues & Variant \\
\hline Input investments & Variant \\
\hline Land prices & Variant \\
\hline Threats to Family Farm Identity & Typical \\
\hline Bridging the gap & Typical \\
\hline Large versus small operations & Variant \\
\hline
\end{tabular}

But it always seems like it always cycles, so if you have a little cushion to where you can make it through a couple bad years, you're probably going to get a couple good years, and it just seems like, weather-wise, rain-wise, it kind of always seems like it balances out.

The core idea of readiness for weather events indicates participants' belief that they needed to be alert and ready to respond to weather events. Although not all weather is necessarily severe, tracking the changes in weather played a critical role in managing both grain and livestock operations. Participant 3 stated, "This is North Dakota-you live with drought, you live with snowstorms. Either you survive or you're done!" 


\section{JUNTUNEN ET AL.}

In the final core idea of the Weather and Climate domain, variable attitudes toward climate change, participants expressed ambivalent beliefs surrounding the existence of climate change. Participant 5, conveying this core idea, stated,

I don't know if we've experienced it [climate change] in North Dakota that much. We hear a lot about it, uh, the climate has been so varying so long in this part of the world. We experience all of the different weather issues. I would say it's [climate change] almost helped us in this part of the world!

It is interesting to note in this quote that climate change is perceived in a positive light. This reflects the recognition by several farmers that this part of the country is experiencing higher levels of moisture and longer growing seasons than it has in the past. Farmers are able to grow some new crops, some of which are relatively profitable, due to these changes.

\section{Technology and Science}

The domain of Technology and Science, which was discussed by all the participants, conveyed the sentiment that science and technology have drastically altered the manner in which these farmers and ranchers approach their work. Within this domain, the core ideas of (1) changing practices, (2) scientific mindedness, (3) handheld devices, and (4) increased efficiency emerged. Participant 8 expressed some fear about such rapid changes to their practices:

It's a technology world! GPS for tractors, satellite mapping for fields, satellite mapping for sprays, and you can carry all that data into your next year when you're out there. This isn't grandpa's agriculture anymore. And it's a scary place to venture into.

The acknowledgement that this is a "scary place" highlights that farmers in this region more actively engaged in precision agriculture techniques and procedures. The abundance of technology and the potential for external or remote control was widely acknowledged as both an opportunity and a potential source of worry among participants.

The core idea of changing practices represents participants' belief that technological advances, such as the advent of chemical fertilizers and pesticides, are viewed as the driving forces to changing farming practices. Participant 3 stated, "I think the biggest land use change occurred in the last 20 or 25 years because of no-till farming. You know when technology came around to kill weeds with chemical instead of with a plow."

The second core idea in this domain was scientific mindedness. This core idea represented the respondents' belief that they have to incor- porate science in their farming and ranching practices. Highlighting this core idea, Participant 8 explained how his family farm was

kind of moving into a new transition phase because our oldest daughter is going to major in animal science and probably move into some DNA and genomic work.... and our younger daughter is kind of a cattle nutrition major. So, we're trying to figure out how in the world we can put all this together, because if I can put all that together, then we'll have quite an operation!

The next core idea in this domain is dependency on and use of handheld devices. This idea represents respondents' recognition of their regular use of handheld radar and GPS devices to monitor weather events and to operate machinery. Participant 9, speaking to the ability to monitor weather, stated,

I get up at 4:30 [am] and ... that is the first thing I do before anything else. I pull up the weather on the iPad and see. You know I have a remote DTN weather station at our farm down south, so I can pull up on my iPad whether it's rained overnight, what the humidity, what the temperature and everything is. Our base of operation is five miles to the north, and that farm is seven miles to the south. So, I know before I get to work whether it's rained down there, if I need to send someone down there to do something, or if I need to go and check for rain or check for hail damage or whatever else.

The core idea of increased efficiency represents the belief that technological advances have improved the efficiency of agricultural producers. For example, Participant 8 asserted,

More efficient, ... I mean we're seeding crops, I mean almost down to the kernel! On how many kernels it should take to seed that field! I mean, it's not quite there yet, but it's amazing. There's no guessing: That's all radar based and GPS lined in. It's amazing when you can cover 640 acres and only be off an inch when you're done.

Participant 5, a lifelong farmer, explained,

Before you'd put in a 16-hour day, you were driving the tractor all day. Now it's pretty much GPS guided, all mapped out, fields all laid out for you. Wherever you go when you are seeding or spraying it shows a map of where you have been.

\section{Emotional and Familial Connectedness}

Throughout the interviews, the participants expressed more than an economic motivation for their profession. For all 19 of the farmers and ranchers, there was an emotional and familial connection to a 


\section{FARMERS’ AND RANCHERS’ BELIEFS AND ATTITUDES}

career working on the land. These sentiments represented the domain of Emotional and Familial Connectedness. Participant 7 highlighted this domain by saying,

Yes, money is important because you have to be able to pay your bills, but we're doing it more with the goal of wanting that lifestyle for our kids and wanting to give them the chance to be in God's creation, I guess, and be a part of the beauty and enjoyment of being out on the land and that kind of thing.

There were three core ideas under this domain: (1) multigenerational, (2) stewardship/responsibility, and (3) passion/love for farming.

The core idea of multigenerational (defined as having multiple generations of a single family working the farm) reflected the fact that many of the participants were part of multigenerational operations. Additionally, this core idea represents the notion that some farming decisions are connected to a multigenerational experience. Some participants stated that their reasoning for some of the decisions made on the farm or ranch was due to what the previous generation did on the farm. Participant 9, a farmer, observed,

If you ask many farmers why they plant what they are planting it's "well my dad or my grandpa used to plant this or used to have it in rotation." And [they] didn't really take a lot of things into consideration that we as modern agriculture do.

The core idea of stewardship/responsibility represented respondents' belief that being a farmer is more about a need to take care of the land and not just make money. Reflecting this core idea, Participant 6 said,

I try to do everything right and take care of the land in a good right way and do it kind of the way you know mother nature intended to do it, so you know there isn't a lot of erosion or things like that-be a good steward of the land is the easiest way to say it.

The third core idea of this domain is passion/love for farming, which reflects the strong connections of these participants to the land. Though it was clear that farming or ranching can be a difficult way to earn a living, it was also clear that there was a strong underlying passion and love for farming and ranching. Participant 6 , conveying this notion of passion and love, stated "I love what I'm doing, if you enjoy it, it isn't work, so I haven't thought about retiring or what I'm going to do later, you know."

\section{Economics}

The domain of Economics, which the majority of the participants endorsed, recognized the impact of complex economic factors related to agricultural practices and decision-making. There were five core ideas under this domain: (1) market fluctuations, (2) government programs, (3) labor issues, (4) input investments, and (5) land prices.

In the core idea of market fluctuations, participants recognized the shifting nature of profitability in farming and ranching, which impact both operations and family livelihood. Conveying the notion of fluctuations and the changing profitability of farming, Participant 8 noted, "It never fails, either one side of my operation is making money, and one side is losing it, and you really hope the side that's makes money is making a lot of money."

The core idea of government programs highlighted the impact and access to government programs and assistance on farming production. Participant 4 explained the impact of government programs, "We recently started planting stuff that has deep roots that penetrated the soil. They [the government] said that improves the soil health. That's one of the things, and this has come down from the government program."

The core idea of labor issues acknowledged the shifts and reductions on the reliance of family labor, which have necessitated the need for external labor sources. The need for more external labor has implications for farming production. Reflecting on the need for external labor sources, Participant 9 noted, "the biggest thing that has hurt us is the shortage of labor. You have to be resourceful where you look for labor."

The core idea of input investments recognized the increased investment costs associated with farming and ranching. These increased investment costs influenced decision-making practices related to farming production and viability. One farmer, Participant 8, noted,

We got to talking about machinery costs, and you know 40 years ago, a lot of ranchers in this county right here, their total expenditures on any equipment might have been $\$ 50,000$. Now, you can't hardly buy one piece of equipment for that.

\section{Threats to Family Farm Identity}

As reported by the majority of the participants, a divide exists between an understanding of agriculture and the general public. This divide in understanding emerged as a typical domain titled Threats to Family Farm Identity. The two core ideas for this domain were (1) bridging the gap and (2) large versus small operations. The participants discussed the need to educate those who are not farmers to increase public understanding of what goes into farming. Participant 10 discussed the importance of educating the public on farmers' passion for their work and the animals they raise:

We're very conscious of letting people know that even though this is how we make our living, we do have a true passion for the animals. It's not just a product to us. We take care of them and their little hearts. 


\section{JUNTUNEN ET AL.}

The core idea of bridging the gap represented participants' acknowledgment of how hard and rewarding their work can be and how they wished there was more understanding from others outside of the agricultural community. As a part of this core idea, several participants expressed a belief that their intent and goals were misunderstood. Participant 1 stated:

One of the biggest things we're fighting from an agricultural standpoint right now is that thought process that's out there. I'm not saying that it's wrong; I just wish they would loosen it a little bit and see our side too, that we're out there earning and doing. You know, when it's 20 below zero in the dead of winter and the well breaks down and it's 10:30 at night, I can't stay in the house. I've got several hundred mouths out there that need me, and I've got to find a water source for them. So I'm out there doing.... And I think in our industry, it would help bridge a lot of gaps [if this was understood].

The second core idea for this domain was large versus small operations. Many of the participants discussed the competition between large and small operations. This competition, they feel, has made it more difficult for smaller operations to stay in business. Reflecting this core idea, Participant 5 stated:

When you're a big farmer and you're making big bucks, whenever another section of land comes up for sale, you can pay for that land up front without actually making money on that for a while. You can pay for it because of the money you're making on your other stuff. Whereas smaller farmers have to be able to make the money off the land right away to be able to pay the loan on it, so it kind of gets to be where the big guys get bigger.

\section{Discussion}

Farmers and ranchers in North Dakota compete with unpredictable weather patterns, emotional and familial connections to both farm practices and their land, economic uncertainty, and social exclusion as well as balance the pros and cons of decisions based on economic conditions and environmental sustainability.

The complexity of findings emerging from this analysis can be more fully integrated into the existing literature in both psychology and agricultural science when viewed through the lens of the theory of planned behavior (TPB; Ajzen, 1991). When discussing the antecedents of an individual's behavior, scholars (Ajzen, 1991; Wiggins, Ostenson, \& Wendt, 2012) have asserted that behavioral intentions (individual beliefs and attitudes, subjective normative beliefs, and behavioral control beliefs) are the best determinants of behavior. Our discussion of the results is therefore framed in the tenets of the TPB, which shape the implications and recommendations from this study.

The domain of Emotional and Familial Connectedness, which we defined as emotional and familial connection to a career working on the land, was endorsed by all the participants. These connections to working the land were expressed by three different core ideas: multigenerational, stewardship, and passion/love for farming. Multigenerational meant that participants in this study were a part of successive generations of family members working in farming or ranching. Additionally, this core idea represents the notion that some of the agricultural decisions were made in guidance with other family members across generations or in line with agricultural practices employed by other family members over the generations. Thus, the results suggest that the participants' feelings toward the land and their families' relationship with the land played a significant role in shaping the participants' own beliefs and attitudes toward agricultural practices. Within the TPB framework, these attitudes reflect the influence of the subjective norm. They may be connected with social pressure, exerted by other family members and the larger agricultural community, to perform or not perform certain agricultural or conservation practices. The participants' attitudes toward these practices may ultimately influence their intentions to engage in conservation practices in the future.

Stewardship, another important facet of connectedness, has been defined as people taking care of and protecting the land (Brown $\mathrm{At}$ Mitchell, 2000). Such care and protection create an obligation to the land and to the use of the land for current and future generations. The emotional connectedness toward their families and agricultural lifestyles, expressed by the majority of the participants, reflected a "sense of place" (Mullendore, Ulrich-Schad, \& Prokopy, 2015, p. 68), which has been found to predict conservation program enrollment and the adoption of environmentally friendly management practices (Mullendore et al., 2015).

The notion of stewardship was also found in the domain of Threats to Family Farm Identity, under the core idea of bridging the gap, in which the majority of the participants expressed concern that their work was not understood by individuals outside of the agricultural community. Participants expressed a desire to convey the importance of their land stewardship to the non-agricultural community. When analyzed from a TPB framework, we believe that the participants' attitudes toward stewardship are connected to perceived social pressures that reflect communal attitudes, passed across the agricultural community, which convey some level of responsibility to the land. These beliefs of land responsibility may influence their future behaviors related to conservation practices. 


\section{FARMERS’ AND RANCHERS’ BELIEFS AND ATTITUDES}

Another salient domain identified in this study concerns the Economics and financial stress related to agricultural practices. The frequent occurrence of financially related beliefs and attitudes associated with conservation practices has been well explored (Lynne et al., 1988; Thompson et al., 2015). Thus, this qualitative result supports the assumed importance of financial concerns as one of the influences on the adoption of conservation practices. The Economics domain explored factors associated with shifts in the market that impact the profitability of the participants' work. Also, participants identified growing concerns with the need for external labor and the increasing costs of machinery and materials. In a state where corporate farming does not exist, there may be greater focus on the financial stability and profitability of farms/ranches due to the need to support the entire family. Thus, in North Dakota, a region with a shorter growing season and where there is greater impact of profits and loss on family functioning and survival, the adoption of more conservation practices may be more strongly influenced by economic factors than in other regions of the United States. This suggests that programs focusing on this northern plains region of the country may want to take into consideration financial stability and profitability when tailoring conservation programs and effectors to farmers and ranchers in the state.

When examining this theme of economic concerns within the TPB, we postulate that economic concerns fit with the third determinant, perceived behavioral control. Beliefs associated with this determinant are assumed to be of primary importance in shaping the behavioral intentions (Ajzen, 1991). If farmers and ranchers believe that their practices have a direct and significant impact on their profits and/or losses, then they may engage in behaviors that lead to increased profits and reduced losses with less concern about long-term environmentally adaptive practices.

We also contextualized economic concerns within a conservation psychology framework. Within this framework, Saunders (2003) viewed factors such as economic concerns as external forces that exert influence on individuals or social systems. In this case, we would argue this influence occurs simultaneously on individual and group levels. Thus, this hypothesized two-fold effect will influence the decisions that individual farmers are making regarding their own agricultural behaviors and the anticipated financial outcome. Farmers and ranchers may therefore retain or change their practices due in part to the financial outcomes of those practices. On a group level, the external factor of economics may influence larger communities of farmers. This suggests a reciprocal process wherein individual decisions could become community practices, and community practices would be adopted by the individuals.

The participants' beliefs and attitudes regarding economics and stewardship highlight an important point of tension in the attitudes and beliefs of farmers. Their commitment to the land and the need to demonstrate a profit and maintain financial security are sometimes in direct conflict. Therefore, one critical aspect of effective conservation efforts would be to work on helping farmers and ranchers align those important values and needs. In addition, the other identified domains and core ideas in the study support the assertion that there are other social beliefs and attitudes that may influence farmers' adoption of conservation practices (Thompson et al., 2015). For this sample of farmers and ranchers, attitudes regarding weather and technology were particularly important.

The domain of Weather and Climate reflected divergent participant beliefs regarding the causes and changes associated with weather patterns and climate. Though some participants expressed beliefs of uncertainty in significant weather and climate change, others expressed beliefs of viewing weather and climate change as being beneficial to agricultural experiences in North Dakota. Based on this conceptualization, we postulate that the participants' individual beliefs and attitudes toward needing to change or adjust their agricultural practices are directly related to the future intention of adopting conservation practices because weather and climate shifts are more closely associated with conservation practices. Further, the unique weather and climate experiences found in this region of the country may contribute to less favorable beliefs toward future intentions and/or the adoption of certain conversation practices.

In the final domain of Technology and Science, the participants' beliefs conveyed the sentiment that science and technology have significantly altered the manner in which farmers and ranchers approached their work in just a matter of a few years. Within the core ideas of changing practices, scientific mindedness, handheld devices, and increased efficiency, the participants expressed a belief that these were the driving forces to changing farming practices. Based on the TPB framework, we believe the beliefs regarding technology and science represent the subjective norm determinant and may also tap into behavioral control. The expectation to use technology is high, which can be a source of social pressure. In addition, technology has resulted in greater efficiencies and outcomes, suggesting more control on the part of the producer. In this way, technology can both promote and potentially deter the adoption of conservation practices.

\section{Limitations}

Although robust findings have emerged, the limitations of the study must be acknowledged. Our data was drawn from a sample of 19 farmers and ranchers in a single state. The region sampled is known for extreme shifts in climate, at times requiring unique farming practices. Hence, the results may not be generalizable to farmers and 


\section{JUNTUNEN ET AL.}

ranchers outside North Dakota. Also, the study had an abundance of White male participants. Although this may represent the majority of farmers and ranchers in the region, this does not represent all farmers and ranchers and may skew some of the results found in this qualitative study. There may be key distinctions in behavior and intentions that are related to gender, race, and region of the country that were not represented in this study. Further, this study collected data from individual interviews and from participants in a focus group. Although these techniques represent two different types of data collection, the results from all the participants were congruent. However, it is important to recognize that employing different types of data collection techniques in qualitative studies may contribute to some noise or even confounds in the results. Thus, it is always important to compare results for differences when using different data collection methods.

\section{Implications and conclusion}

The results of this study have several implications for farmers and ranchers as well as for future theory and research. First, the data from this study seemed to suggest that for family farmers and ranchers in this region of the country, there is a significant and dependent relationship between farming/ranching behaviors and financial success. However, participants also noted that their values and connection to the land were as important as money, in at least some instances. Based on this understanding, it is critical that farmers and ranchers have accurate information about the real costs, benefits, and long-term financial success associated with environmentally adaptive practices. Second, the results support the assertion that, in addition to financial concerns and land stewardship, there were other social beliefs that have the potential to influence future behaviors associated with the adoption of conservation practices (Lynne et al., 1988; Thompson et al., 2015). Thus, it may be valuable for farmers and ranchers to increase their awareness of the interconnecting influences of numerous social and psychological variables, and not just the relationship between economics and stewardship on their future intentions, decisions, and behaviors. Finally, although the participants noted the importance of science-mindedness and scientific methods in their agricultural practices, they had mixed attitudes regarding climate change. It may be necessary to promote more scientific information and education regarding climate change from a nonpoliticized perspective, focusing on the ability to use technology to support, rather than replace (Gardezi $\mathrm{Ct}$ Arbuckle, 2018), conservation adaptation strategies.

As previously noted, the US government has attempted to address environmentally damaging agricultural practices through conservation policies and programs to assist farmers and ranchers in changing to more adaptive farming practices (Claassen \& Ribaudo,
2006; Wilke \&t Morton, 2015). These programs and policies typically offer financial incentives to farmers and ranchers for incorporating these adaptive changes (Baumgart-Getz, Prokopy, \& Floress, 2012). Based on the results from this study, we suggest that organizations also incorporate non-economic, social factors (including stewardship, familial and emotional connectedness, and technology and science) within any trainings, programs, or initiatives aimed at agricultural practices. This is consistent with the assertion by Thompson and colleagues (2015) that in order for long-term cooperative partnerships between the farming community and organizations to meet larger conversation goals, there must be a deeper understanding of those social variables that influence farmer participation in these partnerships and their continued use of conservation practices.

Finally, our findings supported the assertion by Chouinard and colleagues (2008) that although economic and stewardship attitudes are important to consider, there are other important social beliefs and attitudes that must be considered when attempting to understand what may influence future intentions and behaviors regarding conservation practices. Our findings suggest that psychological research and theory development can be improved by looking at a wide set of factors that contribute to conservation practices among farmers and ranchers, and potentially other populations as well. Through such efforts, psychologists can be instrumental in helping to increase participation in conservation programs and policies.

\section{Author Disclosure Statement}

No competing financial interests exist for any of the authors of this study.

\section{Funding Information}

This research was supported by the National Science Foundation, Award \#IIA-1355466.

\section{REFERENCES}

Ajzen, I. (1991). The theory of planned behavior. Organizational Behavior and Human Decision Processes, 50, 179-211.

Arbuckle, J. G., Jr., Morton, L. W., \&t Hobbs, J. (2013). Farmer beliefs and concerns about climate change and attitudes toward adaptation and mitigation: Evidence from lowa. Climatic Change, 118, 551-563.

Baumgart-Getz, A., Prokopy, L. S., \& Floress, K. (2012). Why farmers adopt best management practice in the United States: A meta-analysis of the adoption literature. Journal of Environmental Management, 96, 17-25.

Borges, J. A. R., \& Oude Lansink, A. G. J. M. (2016). Identifying psychological factors that determine cattle farmers' intention to use improved natural grassland. Journal of Environmental Psychology, 45, 89-96.

Brown, J., \&t Mitchell, B. (2000, January). The stewardship approach and its relevance for protected landscapes. The George Wright Forum, 17, 70-79. 
Chouinard, H. H., Paterson, T., Wandschneider, P. R., \&t Ohler, A. M. (2008). Will farmers trade profits for stewardship? Heterogeneous motivations for farm practice selection. Land Economics, 84, 66-82.

Claassen, R., \& Ribaudo, M. (2006). Conservation policy overview. Agricultural Resources and Environmental Indicators, 195, 168-174.

Gardezi, M., \&t Arbuckle, J. G. (2018). Techno-optimism and farmers' attitudes toward climate change adaptation. Environment and Behavior. [Epub ahead of print]; DOI: 10.1177/0013916518793482.

Hansson, H., Ferguson, R., \& Olofsson, C. (2012). Psychological constructs underlying farmers' decisions to diversify or specialise their businesses: An application of theory of planned behaviour. Journal of Agricultural Economics, 63, 465-482.

Hill, C. E. (2012). Consensual qualitative research: A practical resource for investigating social science phenomena. Washington, DC: American Psychological Association.

Hill, C. E., Thompson, B. J., \& Nutt Williams, E. (1997). A guide to conducting consensual qualitative research. The Counseling Psychologist, 25, 517-572.

Lyle, G. (2015). Understanding the nested, multi-scale, spatial and hierarchical nature of future climate change adaptation decision making in agricultural regions: a narrative literature review. Journal of Rural Studies, 37, 38-49.

Lynne, G. D., Shonkwiler, J. S., \&t Rola, L. R. (1988). Attitudes and farmer conservation behavior. American Journal of Agricultural Economics, 70, 12-19.

Melillo, J. M., Richmond, T. C., \& Yohe, G. W. (Eds.). (2014). Climate change impacts in the United States: The third national climate assessment. Washington, DC: U.S. Global Change Research Program. Retrieved from http://nca2014.globalchange.gov/report

Moon, K., Brewer, T. D., Januchowski-Harley, S. R., Adams, V. M., \& Blackman, D. A. (2016). A guideline to improve qualitative social science publishing in ecology and conservation journals. Ecology and Society, 21, doi:10.5751/ES-08663-210317

Mullendore, N. D., Ulrich-Schad, J. D., \& Prokopy, L. S. (2015). US farmers' sense of place and its relation to conservation behavior. Landscape and Urban Planning, $140,67-75$.

Prokopy, L. S. (2011). Agricultural human dimension research: The role of qualitative research methods. Journal of Soil and Water Conservation, 66, 9A-12A.
Prokopy, L. S., Morton, L. W., Arbuckle, J. G., Jr., Mase, A. S., \& Wilke, A. K. (2015). Agricultural stakeholder views on climate change: Implications for conducting research and outreach. Bulletin of the American Meteorological Society, 96, 181-190.

Rejesus, R. M., Mutuc-Hensley, M., Mitchell, P. D., Coble, K. H., \&t Knight, T. O. (2013). U.S. agricultural producer perceptions of climate change. Journal of Agriculture and Applied Economics, 45, 701-718.

Saunders, C. D. (2003). The emerging field of conservation psychology. Human Ecology Review, 10, 137-149.

Thompson, A. W., Reimer, A., \& Prokopy, L. S. (2015). Farmers' views of the environment: The influence of competing attitude frames on landscape conservation efforts. Agriculture and Human Values, 32, 385-399.

USGCRP. (2017). Climate science special report: Fourth national climate assessment, volume I (D. J. Wuebbles, D. W. Fahey, K. A. Hibbard, D. J. Dokken, B. C. Stewart, \& T. K. Maycock, eds.). Washington, DC: U.S. Global Change Research Program. Retrieved from https://science2017.globalchange.gov

Wiggins, B. J., Ostenson, J. A., \& Wendt, D. C. (2012). The relational foundations of conservation psychology. Ecopsychology, 4, 209-215.

Wilke, A. K., \& Morton, L. W. (2015). Climatologists' patterns of conveying climate science to the agricultural community. Agriculture and Human Values, 32, 99-110.

Address correspondence to:

Tamba-Kuii M. Bailey

Counseling Psychology and Community Services

University of North Dakota

231 Centennial Dr. Stop 8255

Grand Forks, ND 58202

E-mail: tambakuii.bailey@und.edu

Received: October 31, 2018

Accepted: June 3, 2019

\section{Appendix A1: Semistructured Interview}

In terms of land use...

1. What have you done (previously)?

Example Follow-Ups:

How has tradition influenced these decisions?

How does your community or other farmers impact these decisions?

How have you adapted your practices over time?

2. What are you currently doing?

How has this been effective/not effective?

How can you tell if it is effective?

3. What do you plan to do in the future?

What markers do you look for to make changes?

What else influences your decision-making?
4. How do you address unexpected events/crises (e.g., oil, major snowfall, drought, etc.)?

5. How have/do economic factors influence(d) your land use decisions?

6. How does the weather/weather patterns affect your farming practices?

How often/how do you check the weather?

How accurate are you at predicting weather?

Has this changed over time?

What impacts changes in the weather? (i.e., human factors, natural factors, both?)

7. How has oil impacted your farming?

8. How does climate change affect your farming practices? 